\title{
Memórias, história e uma aula de Matemática com crianças do Ensino Fundamental
}

Resumo: Neste artigo, estabelecemos alguns diálogos e reflexões em e a partir de uma narrativa sobre movimentos e conhecimentos mobilizados em uma aula de Matemática com uma turma dos Anos Iniciais do Ensino Fundamental. A narrativa foi constituída a partir de alguns resultados de uma pesquisa desenvolvida em uma escola pública de Educação Básica no Município de Campo Grande (MS) durante o período de dois anos. Na narrativa estabelecemos um diálogo com estudos de Mishra e Koehler (2006), que nos ajudaram a discutir sobre o Conhecimento Tecnológico, Pedagógico e do Conteúdo (CTPC), e com estudos de Sanchez (2002, 2003), que nos possibilitaram refletir sobre processos de Integração de Tecnologias Digitais ao Currículo. A partir da narrativa, em que dados da pesquisa são discutidos, foi possível refletir, entre outras problematizações, sobre relações entre o movimento de integração de tecnologias à aula de matemática e o conhecimento do tipo CTPC da professora.

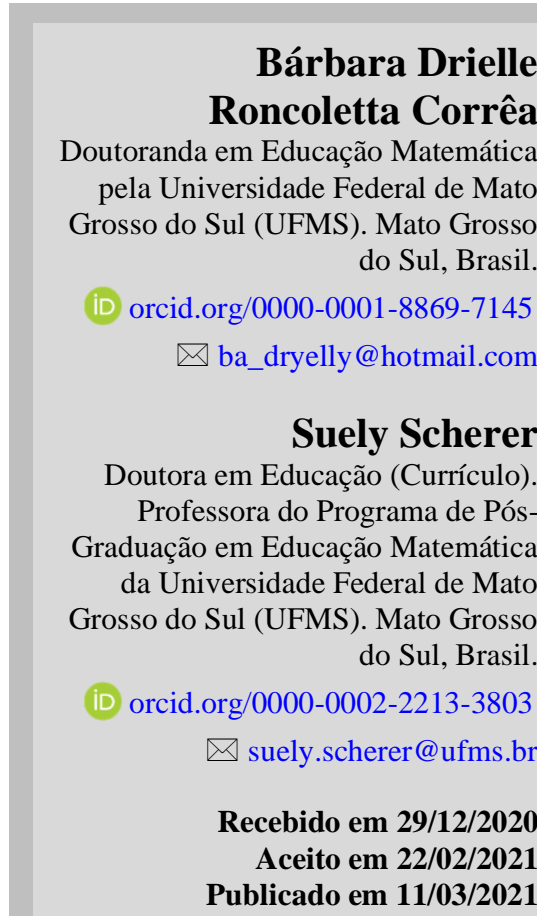

Palavras-chave: Tecnologias Digitais. Ensino de Matemática. Narrativas. Educação Básica.

\section{Memories, history and a math class with Elementary School children}

Abstract: This article establishes some dialogues and analysis, in and from a narrative about movements and knowledge mobilized in a Math class from the early years of Elementary School. The narrative was made from some results of a research in a public school of Basic Education in Campo Grande (MS) for two consecutive years. In this narrative was established a dialogue with studies by Mishra and Koehler (2006), that helped us to discuss Technological, Pedagogical and Content Knowledge (CTPC), and with studies by Sanchez $(2002,2003)$, which enabled to reflect on processes of Integration of Digital Technologies into the Curriculum. Based on the narrative, in which research data are discussed, it was possible to thinking, among other issues, on the relationship between the movement of integrating technologies into the mathematics class and the teacher's CTPC knowledge.

Keywords: Digital Technologies. Mathematics Teaching. Narratives. Basic Education.

\section{Memorias, historia y una clase de matemáticas con niños de Primaria}

Resumen: En este artículo, establecemos algunos diálogos y reflexiones dentro y desde 
una narrativa sobre movimientos y conocimientos que fueron discutidos en una clase de Matemáticas de un curso perteneciente a los primeros años de la Educación Fundamental. La narrativa fue constituida a partir de algunos resultados de una investigación desarrollada en una escuela pública de Educación Básica en el Municipio de Campo Grande (MS) durante el período de dos años. En la narrativa establecimos un diálogo con estudios de Mishra y Koehler (2006), quienes nos ayudaron a discutir el Conocimiento Tecnológico, Pedagógico y de Contenido (CTPC), y con estudios de Sánchez (2002, 2003), que nos permitieron reflexionar sobre los procesos de Integración de Tecnologías Digitales en el Currículo. Sobre la base de esa narrativa se discutió los datos de la investigación y fue posible reflexionar, entre otros temas, sobre la relación entre el movimiento de integración de tecnologías en la clase de matemáticas y el conocimiento del profesor sobre CTPC.

Palabras clave: Tecnologías Digitales. Enseñanza de la Matemática. Narrativas. Educación Básica.

\section{Um breve contar}

[...] nós construímos, reconstruímos e de alguma forma reinventamos o ontem e o amanhã. Memória e imaginação amalgamam-se nesse processo. Mesmo quando criamos os mundos possíveis da ficção, não desertamos do familiar, mas o subjuntivizamos naquilo que poderia ter sido ou no que poderia ser. Por mais que a mente humana tenha exercitado sua memória e refinado seus sistemas de registro, ela nunca consegue capturar o passado de maneira completa e fiel. Por outro lado, ela jamais consegue escapar ao passado. Memória e imaginação são fornecedoras e consumidoras uma da outra (BRUNER, 2014, p. 103).

E assim, inspirado nas palavras de Bruner (2014), este texto se constitui. Um movimento em que contaremos uma história vivida por nós, pesquisadoras, durante dois anos, numa escola pública de Educação Básica. Durante esse período, investigamos processos de integração de tecnologias digitais ao currículo dos Anos Iniciais do Ensino Fundamental e, aqui, iremos apresentar e dialogar com alguns resultados dessa pesquisa.

Para lhes narrar esta história, contamos com imaginação e memórias de nossas vivências, "essa memória não é aquilo que lembra fatos, objetos e sujeitos, mas aquilo que os conhece, inventando-os" (FERNANDES, 2014, p. 902). Diríamos mais, (re)inventando-os. Isso porque não consideramos ser possível reproduzir acontecimentos exatamente como ocorreram, melhor dizendo, a experiência vivida é irrecuperável. Ainda assim, acreditamos poder criar, (re)inventar, (re)produzir, (re)significar acontecimentos vivenciados por nós. Qual o resultado? Outra experiência de tempo presente, que pode ser (re)contada de diferentes maneiras. Aqui, se encontra uma delas, vamos lá... 
Estou conectada. Estamos conectadas. Somos conectadas. Vivemos conectados! Não todos (infelizmente), mas uma grande maioria. Não falamos mais (ou muito pouco) de uma conexão estática e limitada de fios, mas, de uma conexão móvel que (re)configura noções de tempo e espaço, além de nos permitir fazer-pensar muitas coisas do dia a dia, de onde quer que estejamos. Seria, no mínimo, clichê ficar apontando essa diversidade de ações aqui, mas, gostaríamos de enfatizar que o celular com acesso à internet, por exemplo, é um dispositivo tecnológico que nos oportuniza modos outros de ser, pensar, estar e produzir, inclusive, conhecimento.

Pensando nisso, aliás, vivendo diariamente em meio à essa cultura digital, que nos "engole" com informações e conteúdos, consideramos oportuno e necessário refletir sobre possibilidades de integrar tecnologias digitais ao currículo escolar.

No caso deste artigo, o olhar se destina à Educação Básica, mais precisamente, à uma aula que aconteceu em uma turma do $3^{\circ}$ ano do Ensino Fundamental, em uma escola pública, na periferia de Campo Grande (MS). Olhamos, e dialogamos com os alunos durante esta aula, mas, especialmente, nos dedicamos a investigar, com a professora, potencialidades de integração de tecnologias digitais ao currículo em ação. Vale mencionar que, muito mais que essa aula, acompanhamos as ações dessa professora durante dois anos, suas vivências, angústias, dificuldades, anseios, conquistas, superações e muito mais. Mas este é um pequeno spoiler ${ }^{1}$, para mais detalhes, continue acompanhando o desenrolar e o desfecho desta história.

\section{2 (Re)visitando alguns caminhos percorridos}

O que se faz é, tão somente, descrever o caminho construído ao caminhar sem a pretensão de que ele se torne, para alguém, [...] caminho a ser percorrido. (CLARETO, 2007, p. 51-52).

Os caminhos percorridos durante os dois anos em que estivemos na escola não foram poucos. Idas, vindas, voltas, revoltas, vai, vem, faz, refaz, insiste, persiste, só não desiste. Neste artigo, (re)visitamos algumas ações desenvolvidas durante a pesquisa realizada nos anos de 2017 e 2018. A nossa intenção com este texto é apresentar alguns resultados obtidos em nosso estudo e produzir, com eles, um movimento de diálogo e

\footnotetext{
${ }^{1}$ Por Spoiler compreendemos o ato de antecipar alguns fatos sobre de um determinado conteúdo.
} 
problematização. Em outras palavras, conhecer outros caminhos. Mas, antes disso, situaremos brevemente o leitor sobre o cenário da pesquisa.

A pesquisa foi desenvolvida em uma escola da Rede Municipal de Educação no município de Campo Grande. A investigação foi desenvolvida com/nesta escola, pois fez parte de um projeto de pesquisa maior intitulado Integração de tecnologia digitais ao currículo dos Anos Iniciais do Ensino Fundamental: desafios na/para inovação, que foi financiado pela Fundação de Apoio ao Desenvolvimento do Ensino, Ciência e Tecnologia do Estado de Mato Grosso do Sul (Fundect), aprovado no edital FUNDECT/CAPES N ${ }^{\circ}$ 11/2015 - EDUCA-MS - CIÊNCIA E EDUCAÇÃO BÁSICA. O período total de duração da pesquisa financiada foi de trinta e seis meses, de julho de 2016 a junho de 2019 .

Ao todo, cinco professoras da escola foram parceiras da pesquisa. Em nossa produção de dados/informações, optamos por acompanhar durante quatro semestres letivos, uma professora (participante do projeto) e por três semestres letivos suas turmas de alunos do $3^{\circ}$ ano (em 2017) e do $4^{\circ}$ ano (em 2018) do Ensino Fundamental, em aulas de Matemática. Foram dois anos vivenciando o "chão" de escola e produzindo conhecimento em parceria com a professora. Os movimentos realizados durante este período constituíram-se em uma ação de formação continuada em serviço com a proposição das seguintes atividades: elaborar e avaliar planejamentos de aula, realizar estudos e reuniões coletivas, desenvolver algumas oficinas e, ainda, observar algumas aulas de Matemática.

Os encontros para planejamentos aconteciam quinzenalmente na escola e a ideia era pensar em possíveis práticas pedagógicas que em um movimento de integrar tecnologias digitais ao currículo. Sendo assim, tendo em vista um currículo prescrito, pensávamos coletivamente em aplicativos, jogos, vídeos, softwares, entre outras tecnologias que pudessem ser utilizadas com o intuito de potencializar processos de aprendizagens dos alunos, em ações da sala de aula. Importante ressaltar que estes planejamentos não eram levados prontos e, muito menos impostos para serem colocados em prática. Queremos dizer que as professoras sempre tiveram total autonomia para modificar as atividades planejadas, até porque as propostas não eram fechadas, mas, ideias, conhecimentos em (re)construção. Éramos parceiras planejando ações para a sala de aula. 
Neste artigo, escolhemos (re)contar vivências e experiências de uma aula de Matemática que aconteceu no $3^{\circ}$ ano do Ensino Fundamental. Nesta aula, a professora trabalhou o conceito de subtração de números naturais utilizando a lousa digital e o aplicativo Base Blocks Subtraction ${ }^{2}$. Na análise dos dados da pesquisa, problematizamos e realizamos algumas reflexões acerca do Conhecimento Tecnológico e Pedagógico do Conteúdo da professora, amparadas nos estudos de Mishra e Koehler (2006). Além disso, articulamos um diálogo sobre processos de integração de tecnologias digitais ao currículo, tendo em vista a perspectiva estudada por Sanchez (2003).

Na história contada neste artigo, nós estabelecemos um diálogo com estudos de Mishra e Koehler (2006), que nos ajudaram a refletir sobre o Conhecimento Tecnológico, Pedagógico e do Conteúdo $\left(\mathrm{CTPC}^{3}\right)$ e suas possíveis inter-relações, ao discutir as ações da professora na aula. Também dialogamos com estudos de Sanchez (2003), que nos oportunizaram refletir sobre processos de integração de tecnologias digitais ao currículo. Vamos ao diálogo inicial com esses autores...

\section{Um olhar para o Conhecimento Tecnológico e Pedagógico do Conteúdo}

O que é conhecimento? Conhecimento relaciona-se com ordem, desordem, organização? Também! Tem a ver com (re)construção de realidades? E com incompletude, relações, processos? Sim... e, muito mais! Ilusão seria pensar que existe o conhecimento único, absoluto ou, até mesmo, o conhecimento ideal. Morin (2003) afirma que

todo conhecimento constitui, ao mesmo tempo, uma tradução e uma reconstrução, a partir de sinais, signos, símbolos, sob a forma de representações, ideias, teorias, discursos. A organização dos conhecimentos é realizada em função de princípios e regras que não cabe analisar aqui; comporta operações de ligação (conjunção, inclusão, implicação) e de separação (diferenciação, oposição, seleção, exclusão). O processo é circular, passando da separação à ligação, da ligação à separação, e, além disso, da análise à síntese, da síntese à análise. Ou seja: o conhecimento comporta, ao

\footnotetext{
2 O aplicativo Base Blocks Subtraction faz parte da biblioteca virtual NLVM e pode ser acessado pelo link http://nlvm.usu.edu/en/nav/frames_asid_155_g_1_t_1.html?from=topic_t_1.html. No entanto, para realizar o acesso, é preciso utilizar o navegador Internet Explorer.

${ }^{3}$ CTPC - Conhecimento Tecnológico e Pedagógico do Conteúdo corresponde à uma tradução do termo TPACK (Technological Pedagogical Content Knowledge), abordagem estudada por Mishra e Koehler (2006). Blauth (2017) utilizou esta tradução em sua dissertação, a partir de estudos de outros pesquisadores. Optamos, neste trabalho, em utilizar esta mesma tradução do termo.
} 
mesmo tempo, separação e ligação, análise e síntese (p. 24).

E assim também podemos dizer que se constitui conhecimentos discutidos neste texto, que se compõe em meio a emaranhados de questionamentos sobre a vida, melhor dizendo, escola, educação, conhecimentos, professores, formações, currículos, tecnologias, alunos, exclusões, ensino, aprendizagem, práticas sociais, ..., sobre uma diversidade de coisas que coexistem.

Iniciamos discutindo o conhecimento a partir dos estudos de Mishra e Koehler (2006), o Conhecimento Tecnológico e Pedagógico do Conteúdo (CTPC). Segundo esses autores, este conhecimento é produzido nas interrelações de outros três: o Conhecimento do Conteúdo, o Conhecimento Pedagógico e o Conhecimento Tecnológico. São várias as possibilidades que estes conhecimentos têm de se (inter)relacionar, isto é, eles não operam de modo isolado, um depende do outro, o todo e as partes, as partes e todo em um movimento constante de auto-eco-organização ${ }^{4}$. Nesse sentido, não basta que os professores compreendam cognitivamente estes três conhecimentos de modo isolado, é preciso ir além e oportunizar as interrelações possíveis "a fim de encontrar soluções que sejam sensíveis a contextos específicos" (BONSERVIZI e SGRECCIA, 2021, p. 6). A partir das ideias de Mishra e Koehler (2006), na sequência dialogamos um pouco sobre esses conhecimentos.

O Conhecimento do Conteúdo (CC) se refere ao conteúdo específico de uma área do conhecimento, ou seja, é necessário que o professor conheça estruturas, teorias, ideias e, também conceitos que da área, como conhecimentos da Matemática institucionalizada. O Conhecimento Pedagógico $(\mathrm{CP})$ é um tipo de conhecimento que oportuniza que o professor realize ações de diagnóstico, planejamento, desenvolvimento, avaliação, entre outras, considerando diferentes contextos, singularidades e subjetividades.

Já o Conhecimento Tecnológico (CT) é o conhecimento que o professor tem sobre tecnologias. Sejam elas convencionais: livro, lápis, borracha, quadro branco, giz etc.; e sejam elas digitais: computador, vídeos, aplicativos, celular, lousa digital etc. No que diz respeito às tecnologias digitais, este conhecimento envolve tanto a parte operacional, quanto a parte funcional. Por exemplo, instalar e remover programas como softwares,

\footnotetext{
4 Todo organismo vivo é um sistema autopoiético. Isso diz de uma capacidade de auto-organizar, se autoconstruir. Sendo assim, a auto-eco-organização é a ação de que todo organismo vivo possui de se autoproduzir, o tempo todo, nas relações que estabelece com o meio e com o outro (MORIN, 2003).
} 
criar pastas para armazenar arquivos, instalar e calibrar uma lousa digital são ações que se destinam à parte operacional deste conhecimento. Já se pensarmos em ações como explorar um aplicativo, um jogo, um vídeo, ou ainda, utilizar editores de textos, planilhas, e-mails, acessar plataformas online, dentre tantas outras, nos aproximamos da parte funcional destas tecnologias digitais.

E na interação destes três conhecimentos supracitados temos o Conhecimento Tecnológico e Pedagógico do Conteúdo (CTPC), que se compõe pelas relações complexas estabelecidas entre esses conhecimentos. Ao se apropriar de CTPC, o professor pode propor e coordenar ações em movimentos contínuos de integração de tecnologias digitais ao currículo. Mas, que movimentos são esses? Vamos dialogar sobre eles...

\title{
4 Integração, que movimento é esse? Como inicia?
}

Integração de tecnologias digitais ao currículo escolar... Que movimento é esse? Essa integração podemos considerar como sendo um processo que indica movimento, acontece na escola e, também fora dela. Mas, de que escola estamos falando?

\begin{abstract}
A escola, que se constitui como um espaço de desenvolvimento de práticas sociais, se encontra envolvida na rede e é desafiada a conviver com as transformações que as tecnologias e mídias digitais provocam na sociedade e na cultura, e que são trazidas para dentro das escolas pelos alunos, costumeiramente pouco orientados sobre a forma de se relacionar educacionalmente com esses artefatos culturais que permeiam suas práticas cotidianas. (ALMEIDA e SILVA, 2011, p. 05).
\end{abstract}

A escola seria então um espaço físico em que alunos e professores se relacionam diariamente para cumprir "currículos prescritos" e lidar com questões de ensino e aprendizagem? Também. Isso é uma pequena parcela da compreensão que temos sobre escola, afinal a escola também se constitui em espaços virtuais, a exemplo dos movimentos provocados pelos isolamentos sociais decorrentes da pandemia do COVID19. Então, falar de escolas é falar de organismos vivos que se auto-eco-organizam nas relações que estabelecem com o meio, consigo mesmo... Escolas são alunos, professores, equipe de orientação e de direção, pais e responsáveis, comunidade local... e suas interações com diferentes culturas, conhecimentos, currículos prescritos.

E novamente questionamos, o que é então o processo de integração de tecnologias 
digitais ao currículo? Segundo Figueiredo, Lobo da Costa e Llinares (2021, p. 5), “este é um dos desafios que o professor enfrenta no cotidiano escolar: integrar a tecnologia ao currículo e desenvolver a competência de olhar com sentido para o aprendizado do aluno". Buscando compreender um pouco mais o conceito de integração, nos reportamos aos estudos de Sanchez (2002).

Para esse autor, "integrar as TICs é fazer com que façam parte do currículo, enlaçá-las harmonicamente com os demais componentes do currículo. É utilizá-las como parte integral do currículo e não como um apêndice, não como um recurso periférico" (SANCHEZ, 2002, p. 1). Concordamos, em partes, com tal afirmação, isso porque não consideramos que seja possível manter um processo de integração sempre em harmonia conforme ele menciona. Vamos explicar melhor...

A aula vivida muitas vezes destoa do que fora planejado. Nesse sentido, acreditamos que as tecnologias não se integram isentas de desarmonias, tampouco, de pequenos e grandes conflitos. A questão que aqui ressoa é de olhar o processo levando em consideração não componentes excludentes, mas, complementares. Harmonia e (des)harmonia, ensino e aprendizagem, currículo prescrito e currículo em ação, tecnologias digitais e tecnologias manipuláveis, on-line e off-line, ideal e possível, dentre tantas outras binaridades que fazem parte desta relação. Observe que a própria palavra "relação" tensiona que nesses conjuntos, um não existe sem o outro, ao menos não deveria, se interligam para a constituição de lógicas ternárias.

Assim, quando pensamos em processos de integração de tecnologias digitais ao currículo, consideramos práticas pedagógicas que vão "além de práticas esporádicas em espaços delimitados a laboratórios de informática e penetram no cerne dos processos de ensino e aprendizagem, provocando mudanças nas relações com o conhecimento e no currículo" (ALMEIDA e VALENTE, 2011, p. 9). O que queremos dizer com isso? Muitas coisas, especialmente, que ao usar tecnologias digitais em aulas, independentemente do espaço, o professor estabeleça objetivos pedagógicos de modo que a tecnologia escolhida - seja ela um aplicativo, software, vídeo, música, enfim... - possa potencializar o processo de conhecimento em jogo, caso contrário, podemos estar falando de processos outros, não de integração!

Nossa intenção, neste artigo, não é fechar portas, nem definir conceitos, mas, 
dialogar com/sobre eles na tentativa de quem sabe, ampliá-los (ou não). Tendo dialogado, mesmo que brevemente, sobre/com algumas características do que entendemos ser um movimento de integração, precisamos refletir sobre como ele pode iniciar. Sim, iniciar, pois em sendo processo, não se pode finalizar, sempre poderá ser ampliado, continuado...

Para Sanchez (2003), há três níveis no processo de integração, são eles: conhecimento, uso e integração. No primeiro nível, o professor está aprendendo sobre suas funcionalidades de tecnologias, sabe, por exemplo, usar softwares e hardwares. Nessa fase, ele não tem pretensões educativas, o foco é conhecer e explorar tanto potencialidades, quanto limitações dessas tecnologias. Seria este um primeiro movimento para a integração de tecnologias digitais? E ainda, seria possível demarcar o momento exato em que este processo se inicia, separado dos demais? Continuando o diálogo...

No nível do uso, Sanchez (2003) afirma que o professor planeja uma atividade pedagógica com a intenção de uso de alguma tecnologia digital, um aplicativo destinado ao ensino de operações de subtração, por exemplo, no entanto, sem objetivos direcionados à compreensão de conceitos de subtração estudados pelos alunos. $\mathrm{O}$ objetivo nesse nível de integração parece ser o de utilizar alguma tecnologia na aula, no caso, um aplicativo, mas ainda, em um movimento prático que pouco contribui com processos de aprendizagens de conceitos pelos alunos. Sobre este nível, pensamos na seguinte direção:

\footnotetext{
Coloca-se o computador nas escolas, os professores usam, mas sem que isso provoque uma aprendizagem diferente do que se fazia antes, e mais do que isso, o computador fica sendo um instrumento estranho (alheio) à prática pedagógica, sendo usado em situações incomuns, extraclasse, que não serão avaliadas (BITTAR, 2010, p. 220).
}

Sinalizamos, na sequência, uma síntese de uma ação em aula, dentre outras, que traduz as palavras da autora: a professora entrega uma folha aos alunos contendo dez operações de subtração para serem resolvidas utilizando o papel, lápis e borracha. Posteriormente à essa ação, essa professora leva seus alunos à sala de informática para utilizarem um aplicativo que permite verificar se os resultados encontrados por eles, anteriormente, estão ou não corretos e, fim.

Nesta ação que acabamos de descrever utiliza-se a tecnologia para verificação e, deste modo, fica difícil apontar quais seriam os ganhos em relação à compreensão do conceito estudado, até porque não acontece um movimento de interação, os erros e os 
acertos destes alunos não são questionados. Se o professor estiver neste nível de integração, podemos observar a necessidade de provocá-lo a continuar no processo de integração, em direção ao terceiro nível, denominado por Sanchez (2003), de integração.

Neste último nível do processo de integração — a partir dele, consideramos que o professor vai intensificando, continuadamente este nível na relação com os demais Sanchez (2003) defende que as tecnologias precisam estar em consonância com o currículo, integradas e invisíveis. Ou seja, o professor ao planejar uma aula tendo em vista o uso de alguma tecnologia, apresenta intenções pedagógicas que visam potencializar a aprendizagem dos alunos. O objetivo do uso não está na tecnologia e, sim, no processo de construção de conhecimento do aluno. Nessa perspectiva, concordamos com Bittar (2010, p. 220), ao argumentar que

\begin{abstract}
o computador deve ser usado e avaliado como um instrumento como qualquer outro, seja o giz, um material concreto ou outro. E esse uso deve fazer parte das atividades rotineiras de sala de aula. Assim, integrar um software à prática pedagógica significa que o mesmo poderá ser usado em diversos momentos do processo de ensino, sempre que for necessário e de forma a contribuir com o processo de aprendizagem do aluno (grifo da autora).
\end{abstract}

As palavras da autora nos fazem ecoar o seguinte questionamento: Para vivenciar um processo de integração é necessário que as tecnologias digitais sejam utilizadas em todas as práticas do professor, independentemente dos espaços escolhidos e objetivos estabelecidos? Esta é uma questão que nos convida a refletir e, portanto, convidamos você, leitor, a fazer o mesmo. Sem a pretensão de esgotar as possibilidades de respostas, arriscamos dizer que não, até mesmo pelas discussões construídas até aqui! Nossa intenção não é, de forma alguma, incentivar que tecnologias como lápis, papel, quadro, giz etc., sejam retiradas de sala de aula. O que gostaríamos de evidenciar, é que estas não sejam as únicas diante de tantas outras, como as digitais.

Conhecimento, uso e integração... Seriam estes níveis hierárquicos? O processo de integração é linear? Para dizer que um certo movimento é ou não de integração, temse que passar, necessariamente, pelos três níveis apresentados aqui? Respostas não trazemos, mas, finalizaremos esta seção com um excerto que nos ajuda a pensar: "tecnologias e aulas, no sentido de integração, não são elementos disjuntos, se misturam, tornam-se algo único, constituem um ambiente de aprendizagem" (SCHERER, 2015, p. 6). Ah! E não esqueça de pensar no processo, mas lembre-se, não se limite a ele. 
Integração é processo, e movimento, e interação, e (des)continuidade, e flexibilidade, e imprevisibilidade, e complexidade, e ...

Quer acompanhar um pouco de como aconteceu um dos movimentos de aula com a professora que foi nossa parceira de pesquisa na escola? É só continuar "conectado" na nossa história.

\section{Uma aula de Matemática com a lousa digital e o aplicativo Base Blocks Subtraction}

Dia vinte e um de agosto do ano de 2017, segunda-feira, aula de Matemática. Lembro que neste dia, ao chegar na sala, - apenas uma das pesquisadoras fez a observação da aula - me deparei com as carteiras dispostas de um modo diferente do habitual. A professora organizou seis grupos, sendo que cinco destes grupos eram formados por quatro alunos e um grupo era formado por cinco alunos. Perguntei a ela, como havia feito a escolha dos alunos de cada grupo e ela disse: "coloquei alunos com mais facilidades e outros com mais dificuldades em aprender, para que se ajudassem, pensei em um modo de trabalharem mais coletivamente, pois quando trabalhamos com a lousa digital, o coletivo funciona bem". Sobre esta configuração da sala, fiquei pensando que também faz parte de movimentos de integração de tecnologias ao currículo e, inclusive, atitudes como esta da professora, podem modificar envelhecidos rigores escolares, neste caso, das cadeiras enfileiradas.

Como sempre, antes de caminhar até o fundo da sala para observar a aula, fui cercada por alguns alunos e recebi abraços, muito carinho, até que consegui me sentar. A professora trabalharia, naquela aula de 50 minutos, algumas atividades envolvendo a operação de subtração com recurso ${ }^{5}$ e, para isso, planejou usar a lousa digital e o aplicativo Base Blocks Subtraction. Para a minha surpresa, os alunos não mostravam tanto alvoroço - um comportamento bem distinto de outras aulas observadas/acompanhadas por mim - ao saber que usariam também tecnologia digital na aula e não apenas lápis e

\footnotetext{
${ }^{5}$ Por subtração sem recurso compreendemos como sendo aquelas em que ao subtrair unidades simples, não seja necessário desagrupar nenhuma dezena, em outras palavras, a quantidade de unidades simples é suficiente para realizar a operação e obter o resultado, por exemplo, $8-5=3$. Já por subtração com recurso, compreendemos sendo aquelas em que é preciso desagrupar, no mínimo, uma dezena para que seja possível realizar a operação e obter o resultado, por exemplo, $15-6=9$.
} 
caderno.

Além disso, já não se via mais os alunos levantando-se de seus lugares para ir representar animais e outros objetos na sombra do projetor. De certo modo, essa tecnologia digital parecia estar, aos poucos, se naturalizando naquele espaço. Isso me remete a processo, lembram-se dele? Fiquei pensando: é bom que se naturalize? Pode ser, mas esperamos que os alunos continuem eufóricos nas aulas, queiram participar, interagir, aprender! Vou contar a vocês, agora, como se deu a dinâmica da aula...

Inicialmente, a professora explicou alguns comandos aos alunos, a partir da projeção do aplicativo na Lousa Digital. Isso porque ela havia optado por usar um aplicativo diferente daquele que eles já conheciam. Este, inclusive, não foi sugestão nossa (pesquisadoras da Universidade), mas escolha da professora. E esse era um movimento desejado durante a pesquisa na parceria com as professoras da escola. Esta atitude nos mostra, além de autonomia, indícios de que a professora mobilizou, nesta/para esta aula, conhecimento do tipo CTPC, já que articulou conhecimento do conteúdo, conhecimento da tecnologia e conhecimento pedagógico. Melhor dizendo, externalizou conhecimento sobre a tecnologia escolhida; tal escolha se deu em função do conteúdo que precisava explorar com os alunos e, ainda, optou por um caminho metodológico que pudesse favorecer a construção de conhecimentos dos alunos sobre o conceito de subtração. É possível perceber melhor este movimento na sequência da aula. Observemos o diálogo a seguir...

Professora: A primeira subtração que faremos é 67 - 28. Quantas dezenas eu preciso incluir'?

Alunos em coro: Seis.

Professora: E quantas unidades?

Alunos em coro: Sete.

Professora: Agora precisamos representar o 28 que é a quantidade que precisamos retirar. Quantas unidades e quantas dezenas eu preciso incluir?

Alunos em coro: Oito unidades e duas dezenas.

Vale observar que neste diálogo a professora poderia levar os alunos a construírem a ideia de que na quantidade 67 tem apenas 7 unidades, e não 67, e que na quantidade 28 , há 8 unidades, ao invés de 28. Esse encaminhamento de aula, sem mais questionamentos

\footnotetext{
${ }^{6}$ Incluir no sentido de que representar no campo destinado às dezenas no aplicativo.
} 
por parte da professora, pode desenvolver esse tipo de conhecimento, que pode incorrer em erro de interpretação no campo da Matemática. Os questionamentos poderiam ser do tipo: quantas unidades que não puderam ser agrupadas em dezenas temos nesta representação de número?

Após ter realizado a representação no aplicativo com a ajuda dos alunos, a professora chamou Marcos, nome fictício de um aluno, para resolver a subtração representada na lousa digital. Na sequência, ela questionou o aluno sobre como ele faria a resolução da operação, e o diálogo continuou...

Marcos: Eu vou começar pelas unidades.

Professora: É isso pessoal? (Se referindo aos demais alunos da turma).

Alunos em coro: Siiiiiiiiiiiiiiiiiiiiiiiimmmmmmmmm... (O sim foi exagerado assim mesmo).

Professora: Você tem sete unidades e precisa retirar oito, é possível?

Marcos: Não tenho oito unidades para tirar aqui, mas posso desmontar uma dezena, aí dá.

Professora: Desmontar?

Marcos: É, levar essa barra na coluna das unidades pra ficar separadas.

Alice: É desagrupar Marcos.

Marcos: Isso que quis dizer.

O aluno realizou o movimento que comentou, desagrupou uma dezena e todos visualizaram as dez unidades que representam a dezena, separadas e, a partir disso, ele retirou as oito unidades solicitadas. A professora perguntou à turma se o que Marcos havia feito estava correto, obtendo deles um retorno favorável. Ao passo que os alunos iam interagindo coletivamente e um deles resolvendo a operação no aplicativo, a professora seguia articulando no quadro o registro aritmético da operação, sempre suscitando questionamento aos alunos, para que eles fossem apontando respostas e, assim, construindo conhecimentos sobre o conceito de subtração.

A professora explorou, inclusive, a questão da expressão "empresta”, utilizada por alguns alunos da turma. Para tanto, explorou no Base Blocks Subtraction, com a lousa, alguns desagrupamentos para que os alunos fossem observando, ao visualizar o desagrupamento, que não se estava emprestando quantidades, apenas desagrupado dezenas, como no exemplo anterior... O que é possível pontuar com essa postura da professora? Várias coisas, dentre elas, indícios de que ela estava mobilizando 
Conhecimento Tecnológico de Conteúdo, isso porque ela esclarece, com o auxílio da tecnologia digital, uma questão importante sobre o conceito matemático que se ignorada pode incorrer em compreensões equivocadas por parte dos alunos.

Ainda nesta aula, foram exploradas mais duas operações de subtração com recurso. O movimento que aconteceu foi semelhante ao narrado aqui, isto é, a professora chamou um aluno para resolver a operação usando a lousa e, simultaneamente, foi envolvendo os demais alunos da turma na mesma atividade. A interação aconteceu a partir de questionamentos da professora e solicitações para que os alunos auxiliassem o colega que estava à frente da sala, manipulando o aplicativo a partir da Lousa Digital. Além disso, a professora explorou o registro aritmético em paralelo às ações e representações no aplicativo, ações estas que possibilitavam uma compreensão visual, um processo diferente do que ocorreria se fosse realizado apenas no ambiente lápis, caderno e quadro branco. Isso nos leva a pensar em processos de tecnologias e aulas num movimento descrito por Sanchez (2003) como sendo de integração.

Antes de finalizar esta narrativa da aula, é importante pontuar o porquê chegamos à esta consideração. Após ter observado movimentos da professora no decorrer dos cinquenta minutos de aula, foi possível perceber que a tecnologia não parecia um recurso periférico à aula, pelo contrário, aparentava fazer parte do todo, estava integrada ao movimento da aula, ao movimento de ensino da professora, ao movimento de aprender dos alunos, como qualquer outra tecnologia - lápis, quadro branco, cadernos, borracha, caneta, ... - que a professora dispunha para trabalhar o conteúdo de subtração naquele momento. $\mathrm{O}$ aplicativo utilizado não ganhou destaque na aula no sentido de ser o foco dela, sua presença se mostrava invisível naquele ambiente, tanto pela professora, quanto pelos alunos, o objetivo e foco da aula destinava-se à compreensão da operação de subtração com recurso.

Além disso, movimentos de aprender subtração com uso da linguagem digital foram potencializados, pois diferente de registros de subtração apenas em quadro branco, dezenas foram sendo desagrupadas dinamicamente ao serem representadas por barras e cubos. As retiradas (subtrações) de unidades e de dezenas solicitadas nas tarefas propostas aconteciam de maneira natural, a partir de alguns cliques ou arrastos com toque de um dos alunos da turma na lousa digital, acompanhados/observados/orientados pelos demais colegas e professora. 
Pudemos notar evidências de que o aplicativo escolhido foi usado de modo integrado a outros materiais pedagógicos e, também, o objetivo da aula estava voltado a processos de aprendizagem dos alunos, articulado ao processo de ensino planejado e desenvolvido - com outros coloridos e movimentos a partir do planejado — pela professora.

\section{Como esta história termina?}

Poderíamos dizer, nos inquietando... Tomadas por muitas questões que ainda nos incomodam, optamos por propor e refletir sobre algumas delas. São questões nossas, mas, podem (ou não) também ser questões suas...

— Quer dizer que as tecnologias digitais resolvem os problemas da Educação?

O objetivo deste artigo não foi levantar a bandeira da tecnologia como possível solucionadora de problemas, mas, suscitar alguns diálogos, reflexões e possibilidades que possam oportunizar maneiras outras de produzir conceitos e conhecimentos quando pensamos em aulas, currículos, escolas... Conforme reflexão apresentada no início deste texto, a conexão permeia a existência de muitas pessoas na sociedade, deste modo, é coerente e necessário pensar a escola, organismo vivo, como parte integrante deste cenário.

— O que é possível dizer sobre/com os conhecimentos aqui discutidos?

A partir da história aqui (re)construída pudemos perceber que Conhecimento Tecnológico e Pedagógico do conteúdo parece favorecer um movimento compreendido por Sanchez (2003) como integração de tecnologias digitais ao currículo. Em outras palavras, a construção de conhecimentos do tipo CTPC parece ser um movimento imbricado ao processo de integração de tecnologias digitais ao currículo, de forma recorrente e recursiva. Essa consideração se justifica, em parte, ao observar os movimentos da professora que narramos neste artigo. Vamos explicar mais!

Em todos os momentos que identificamos a mobilização de conhecimento do tipo CTPC pela professora, imbricados a ela, era possível observar o movimento de integração de tecnologias digitais ao currículo. A professora escolheu trabalhar com a lousa digital e o aplicativo Base Blocks Subtraction com o intuito de que o movimento de 
aprendizagem dos alunos acontecesse de modo distinto do processo feito no ambiente lápis e papel - a intenção não é diminuir a importância deste ambiente, apenas pensar um processo outro. No aplicativo é possível arrastar os cubinhos, agrupar e desagrupar dezenas, centenas, sem a ideia de que algo está sendo trocado e, realmente, não há trocas, apenas agrupamentos e desagrupamentos na base decimal. Mais que isso, a professora proporcionou, em sua prática em sala de aula, interação entre os alunos e construção coletiva e ativa de conhecimentos.

- Conseguiríamos dizer o momento exato em que a integração de tecnologias digitais se iniciou? Como isso se justifica? E o conhecimento do tipo CTPC requer que tipo de atitude da professora ao planejar uma aula?

Pensamos que não, não há um momento exato, pois integração é um processo, é (são) movimento(s), são conhecimentos que se vivenciam na interrelação com outros conhecimentos, pessoas, objetos, tecnologias... Há um marco de início de processo que não é possível ser demarcado. Lembram-se da palavra processo? Então, ela cabe bem aqui. Entre outras coisas, tanto construção de conhecimento do tipo CTPC quanto integração são processos.

São processos que exigem do professor e professora escolhas relacionadas à formação continuada e a assumir atitudes relacionadas à persistência, criatividade, diálogo, conexão... Junto com estas escolhas, por vezes, se vivencia processos repletos de obstáculos e dificuldades em/na relação com o espaço da escola, tempo da escola, pessoas que também a constituem... Mas, se impulsionados por um querer, um agir, um tempo que são intrínsecos a cada indivíduo, seguiremos como professores vivenciando esses e outros processos de apreender a profissão e seus desafios.

Sobre o conhecimento do tipo CTPC, esse requereu da professora parceira sensibilidade para pensar/planejar/vivenciar uma dinâmica de aula, integrando tecnologias digitais e levando em consideração contextos únicos. Além do movimento próprio da professora, ao se pensar/vivenciar processos de integração de tecnologias ao currículo, foram observados fatores específicos da escola, particularidades de cada turma, criança, cultura, necessidades individuais e coletivas, enfim, fatores ímpares que sempre requerem articulações, também ímpares.

Pela narrativa da aula aqui apresentada, podemos considerar que a professora 
conseguiu mobilizar este tipo de conhecimento para ensinar subtração com tecnologias digitais. Mas, esse é apenas um ponto dentre tantos outros que poderíamos discutir sobre os conhecimentos e movimentos dessa professora, com seus alunos.

Para concluir... para refletir... para iniciar... para continuar... Deixamos aqui algumas questões: Como discutir a integração de tecnologias digitais em tempos de isolamento, em que todos fomos levados a viver uma escola, longe do espaço físico em que ela se constituiu, como o provocado recentemente pela pandemia do COVID-19? Como pensar essa escola a partir de dois grupos: os conectados e os que ainda não possuem conexão? Ainda são muitos os que fazem parte deste último grupo e este cenário muito nos preocupa quando investigamos processos de integração de tecnologias digitais ao currículo.

Nesse sentido, dividimos a urgência e a responsabilidade com você leitor, leitora... Como pensar a integração de tecnologias digitais para não omitir essa diferença e, também, outras? Ou melhor, como educar para/nas diferenças? Como vivenciar processos educacionais com integração de tecnologias digitais ao currículo, também fora do espaço físico da escola? Que práticas sociais, políticas e públicas poderiam ser implementadas para que este lugar (sem conexão) possa ser de quase ninguém?

\section{Referências}

ALMEIDA, Maria Elizabeth Bianconcini; SILVA, Maria da Graça Moreira da. Currículo, Tecnologia e Cultura Digital: espaços e tempos de web currículo. e-Curriculum, São Paulo, v. 7, n. 1, p. 1-19, jan./abr. 2011.

ALMEIDA, Maria Elizabeth Bianconcini; VALENTE, José Armando. Tecnologias $e$ currículo: trajetórias convergentes ou divergentes? São Paulo: Paulus, 2011.

BITTAR, Marilena. A escolha do software educacional e a proposta didática do professor: estudo de alguns exemplos em Matemática. In: (Org.) BELINE, Willian; COSTA, Nielce Meneguelo Lobo da. Educação Matemática, Tecnologia e Formação de Professores: algumas reflexões. Campo Mourão: Editora da FECILCAM, 2010, p. 215-242.

BLAUTH, Ivanete Fátima. Prática de Ensino em um curso de Licenciatura em Matemática: uma análise sobre conhecimentos tecnológicos e pedagógicos de conteúdo. 2017. 153f. Dissertação (Mestrado em Educação Matemática) — Instituto de Matemática. Universidade Federal do Mato Grosso do Sul. Campo Grande. 
BONSERVIZI, Virginia Magali; SGRECCIA, Natalia Fátima. Articulação de tecnologias por meio da carreira Professor de Matemática da Universidade Nacional de Rosario. Educação Matemática em Debate, Montes Claros, v. 5, n. 11, p 1-26, 2021.

BRUNER, Jerome. Fabricando histórias: direito, literatura, vida. Tradução de Fernando Cássio. São Paulo: Letra e Voz, 2014.

CLARETO, Sônia Maria. Espaço escolar e tornar-se o que se é: educabilidades e a constituição de novos modos de existir a partir do pensamento de Nietzsche. In: LOPES, Jader Janner Moreira; CLARETO, Sônia Maria. (Org.). Espaço e Educação: travessias e atravessamentos. Araraquara: Junqueira \& Marin, 2007, p. 43-56.

FERNANDES, Filipe Santos. Biografia do Orvalho: considerações sobre narrativa, vida e pesquisa em Educação Matemática. Boletim de Educação Matemática, Rio Claro, v. 28, n. 49, p. 896-909, ago. 2014.

FIGUEIREDO, Sonner Arfux de; LOBO DA COSTA, Nielce Meneguelo; LLINARES, Salvador. Olhar profissional para a docência com tecnologia: um estudo na formação continuada. Educação Matemática Debate, Montes Claros, v. 5, n. 11, p. 1-23, 2021.

MISHRA, Punya; KOEHLER, Matthew. J. Technological Pedagogical Content Knowledge: a framework for teacher knowledge. Teachers College Record, Columbia, v. 108, n. 6, p. 1017-1054, jun. 2006.

MORIN, Edgar. A cabeça bem-feita: repensar a reforma, reformar o pensamento. Tradução de Eloá Jacobina. 8. ed. Rio de Janeiro: Bertrand Brasil, 2003.

SÁNCHEZ, Jaime H. Integración curricular de las TICs: conceptos e ideas. In: CONGRESSO IBERO-AMERICANO INFORMÁTICA EDUCATIVA, 6, 2002, Vigo. Actas del IE2002. Vigo: RIBIE, 2002, p. 1-6.

SÁNCHEZ, Jaime H. Integración curricular de TICs: concepto y modelos. Enfoques Educacionales, Santiago, v. 5, n. 1, p. 51-65, 2003.

SCHERER, Suely. Integração de Laptops Educacionais às aulas de Matemática: perspectivas em uma abordagem construcionista. In: ROSA, Maurício; BAIRRAL, Marcelo Almeida; AMARAL, Rúbia Barcelos. (Org.). Educação Matemática, Tecnologias Digitais e Educação a Distância: pesquisas contemporâneas. São Paulo: Livraria da Física, 2015, p. 163-186. 